\title{
PENERAPAN MEDIA PEMBELAJARAN INTERAKTIF BERBASIS MULTIMEDIA PADA MATA KULIAH SISTEM PENDUKUNG KEPUTUSAN
}

\author{
Rohmat Indra Borman', Apriansyah ${ }^{2}$ \\ 1,2 Fakultas Teknik dan Ilmu Komputer (FTIK), Universitas Teknokrat Indonesia \\ Jl. Z. A. Pagar Alam No.9 -11, Labuhan Ratu, Kedaton, Kota Bandar Lampung, Lampung \\ rohmat_indra@teknokrat.ac.id, ${ }^{2}$ apriansyah@gmail.com
}

\begin{abstract}
ABSTRAK
Media dalam pembelajaran memudahkan peserta didik dalam belajar, memberikan pengalaman konkrit, menarik perhatian, mengaktifkan indera, dan membangkitkan dunia teori dengan realitanya. Sistem pendukung keputusan merupakan salah satu materi yang diajarkan diperkuliahan yang memberikan pengetahuan kepada mahasiswa tentang metode-metode yang dapat diimplementasikan kedalam program kpmputer guna membantu dalam pengambilan keputusan. Yang menjadi kendala mahasiswa dalam mempelajari materi sistem pendukung keputusan adalah terdapat proses perhitungan pada metode-metode sistem pendukung keputusan. Untuk mempermudah dalam memahami metod-metode yang ada pada materi sistem pendukung keputusan dibutuhkan media pembelajaran yang interaktif dan menarik. Terdapat tiga tipe gaya belajar pada umumnya yaitu visual, audiotorial dan kinestetik. Sebagai salah satu alternatif tiga gaya belajar tersebut dapat digunakan dalam pengembangan media pembelajaran yang biasanya disebut sebagai metode multisensori. Pada penelitian ini dilakukan pengembangan media pembelajaran interaktif berbasis multimedia menggunakan pendekatan multisensori yang menggabungkan audio, visual dan kinestetik pada media pembelajaran matakuliah sistem pendukung keputusan. Proses pengembangan media pembelajaran digunakan metode pengembangan multimedia Luther-Soetopo (2003) yang meliputi tahap concept, design, material collecting, assembly, testing dan distribution. Hasil pengujian dari tanggapan dan respon pengguna terhadap media pembelajaran sistem pendukung keputusan mendapatkan nilai rata-rata keseluruhan sebesar $83 \%$ dan termasuk dalam kategori baik.
\end{abstract}

Kata kunci: media pembelajaran, multimedia, multisensori, sistem pendukung keputusan

\section{PENDAHULUAN}

Dalam proses pembelajaran diperguruan tinggi, agar mahasiswa dapat mencapai tujuan belajar yang efektif dan efisien maka diperlukan sebuah media pendukung dalam mencapai tujuan pembelajaran yang diharapkan. Media dalam pembelajaran berfungsi memperjelas pesan yang disampaikan oleh pengajar, selain itu media juga berfungsi sebagai alat bantu mengajar (Sudjana \& Rivai, 2011). Media memudahkan peserta didik dalam belajar, memberikan pengalaman konkrit, menarik perhatian, mengaktifkan indera, dan membangkitkan dunia teori dengan realitanya. Proses belajar mengajar pada dasamya juga merupakan proses komunikasi, sehingga media yang digunakan dalam pembelajaran disebut media pembelajaran (Falahudin, 2014). Media pembelajaran yang sering digunakan dalam penyampaian materi perkuliahan adalah berbentuk slide presentasi. Slide presentasi yang digunakan dalam kegiatan belajar mengajar berupa tampilan visual statis yang dapat dilihat mahasiswa pada saat perkuliahan dikelas berlangsung.

Sistem pendukung keputusan merupakan salah satu materi yang diajarkan diperkuliahan pada program studi sistem informasi maupun informatika. Mata kuliah ini memberikan pengetahuan kepada mahasiswa tentang metode-metode yang dapat diimplementasikan kedalam program kpmputer guna membantu dalam pengambilan keputusan. Kesulitan mahasiswa dalam mempelajari materi sistem pendukung keputusan adalah terdapat proses perhitungan pada metode-metode sistem pendukung keputusan. Ada beberapa materi pada matakuliah sistem pendukung keputusan yang melibatkan perhitungan dalam penyelesainya. Pemodelan pada beberapa pembahasan sistem pendukung keputusan menggunakan pemodelan matematika. Hasil studi TIMSS menunjukan bahwa peringkat prestasi siswa Indonesia pada bidang matematika pada 1999, 2003, 2007, dan 2011 berturut turut 34 dari 38 negara, 34 dari 45 negara, 36 dari 49 negara, dan 38 dari 42 negara. Hal ini menunjukan prestasi siswa dalam pembelajaran matematika perlu ditingkatkan.

Setiap peserta didik memiliki kekuatan pembelajaran sensorik yang biasa disebut dengan gaya belajar (Praveen, 2011). Terdapat tiga modalitas (type) dalam gaya belajar yaitu visual, auditorial, dan kinestetik sebagai salah satu alternatif yang dapat digunakan dalam pengembangan media pembelajaran yang biasanya disebut sebagai metode multisensori. Kelebihan metode multisensori adalah dapat melibatkan individu dengan berbagai gaya belajar visual, auditori, maupun kinestetik. Metode multisensori dapat diimplementasikan pada media pembelajaran dalam bentuk multimedia. Multimedia merupakan kombinasi beberapa media seperti video, audio dan teks pada satu media (Roblyer dan Doering, 2010). Pada penelitian ini dilakukan pengembangan media pembelajaran interaktif berbasis multimedia menggunakan pendekatan multisensori 
yang menggabungkan audio, visual dan kinestetik pada media pembelajaran matakuliah sistem pendukung keputusan.

\section{LANDASAN TEORI}

\section{A. Media Pembelajaran}

Istilah media berasal dari bahasa Latin yang merupakan bentuk jamak dari "medium" yang secara harafiah berarti perantara atau pengantar. Makna umumnya adalah segala sesuatu yang dapat menyalurkan informasi dari sumber informasi kepada penerima informasi (Falahudin, 2014). Menurut Arief, dkk (2009) media pembelajaran mempunyai manfaat sebagai berikut:

1. Memperjelas penyajian suatu pesan agar tidak terlalu bersifat verbalistis

2. Mengatasi keterbatasan ruang, waktu dan daya indera.

3. Dengan menggunakan media pembelajaran secara tepat dan bervariasi dapat mengatasi sikap pasif siswa.

4. Dengan sifat yang unik pada siswa juga dengan lingkungan dan pengalaman yang berbeda-beda, sedangkan kurikulum dan materi pembelajaran yang sama untuk setiap siswa, masalah ini dapat diatasi dengan media pembelajaran dalam kemampuannya:
a. memberikan perangsang yang sama.
b. menyamakan pengalaman.
c. menimbulkan persepsi yang sama.

\section{B. Multimedia}

Menurut Darma dan Ananda (2009) multimedia, ditinjau dari bahasanya, terdiri dari 2 kata, yaitu multi dan media. Multi memiliki arti banyak atau lebih dari satu. Sedangkan medi merupakan bentuk jamak dari medium, juga diartikan sebagai saran, wadah, atau alat. Multimedia diartikan sebagai suatu penggunaan gabungan beberapa media dalam menyampaikan informasi yang berupa teks, grafik atau animasi grafis, movie, video, dan audio (Priyanto, 2009). Multimedia meliputi hypermedia dan hypertext. Hypermedia yaitu suatu format presentasi multimedia yang meliputi teks, grafis diam atau animasi, bentuk movie, video dan audio. Hypertext yaitu bentuk teks, diagram statis, gambar dan tabel yang ditayangkan dan disusun secara tidaklinier. Istilah multimedia sendiri dapat diartikan sebagai transmisi data dan manipulasi semua bentuk informasi, baik berbentuk kata-kata, gambar, video, musik, angka, atau tulisan tangan di mana dalam dunia komputer, bentuk informasi tersebut diolah dari dan dalam bentuk data digital. Sedangkan menurut Yoanes (2010) multimedia didefenisikan sebagai komunikasi yang menggunakan kombinasi antara berbagai media yang menggunakan kombinasi antara berbagai media yang berbeda dan mungkin melibatkan komputer didalamnya. Unsur yang terdapat dalam multimedia ini sesuai dengan yang telah dijelaskan Hofstetter (2001) dalam buku Multimedia Literacy yaitu suara, animasi, video, grafik, dan teks.

\section{METODE PENELITIAN}

Dalam penelitian ini, metode yang digunakan adalah metode pengembangan multimedia yang dikembangakan oleh Luther-Souteopo. Menurut Luther, dalam Sutopo (2003) pengembangan sistem multimedia dilakukan berdasarkan enam tahap yaitu: concept, design, material collecting, assembly, testing, distribution seperti gambar berikut:

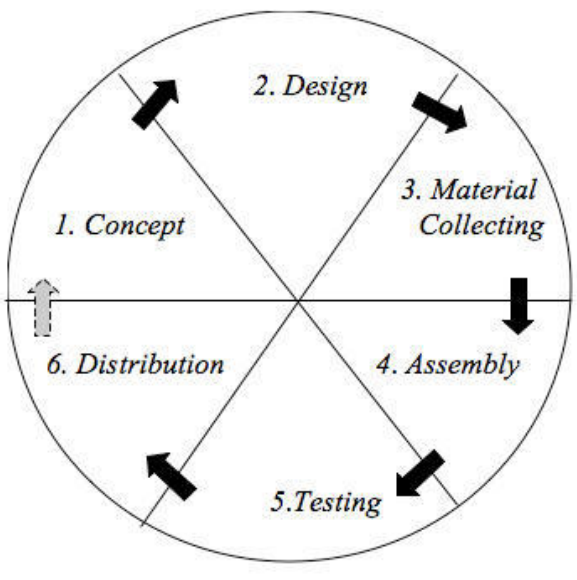

Gambar 1. Model Pengembangan Multimedia 


\section{A. Menentukan Konsep (Concept)}

Pada tahap ini untuk menentukan tujuan, jenis, kegunaaan dan siapa saja yang akan menjadi sasaran dalam pembuatan aplikasi multimedia. Pada penelitian ini tujuan dari pengembangan media pembelajaran sistem pendukung keputusan berbasis multimedia adalah untuk membantu mahasiswa dan dosen dalam proses pembelajaran. Pada media pembelajaran sistem pendukung keputusan berbasis multimedia, menggunakan pendekatan multisensori, yaitu menggabungkan gaya belajar visual, audio dan kinestetik. Konsep multisensori sesuai dengan unsur multimedia, yaitu suara, teks, gambar, animasi dan video. Pada visual media pembelajaran ini menggunakan teks, gambar, dan animasi yang interaktif, media pembelajaran ini juga menggunakan audio yaitu berupa narasi pada materi-materi sistem pendukung keputusan. Sedangkan pada kinestetik, media pembelajaran ini terdapat soal-soal evaluasi yang menuntut mahasiswa untuk melakukan gerakan atau kinestetik dalam mengerjakan soal evaluasi. Mahasiswa dan dosen pada mediam pembelajaran ini memiliki akses yang berbeda. Dosen pada media pembelajaran ini dapat melihat materi, quiz dan rekap nilai. Sedangkan mahasiswa dapat mengakses materi, quiz dan perkembanganku. Untuk lebih jelasnya dapat dilihat pada tabel 1 deskripsi konsep berikut ini :

Tabel 1. Deskripsi Konsep

\begin{tabular}{|l|l|}
\hline Judul & Pengembangan Media Pembelajaran Sistem Pendukung Keputusan Berbasis Multimedia \\
\hline Audiens & Mahasiwa dan dosen \\
\hline Durasi & Tidak terbatas (Unlimited) \\
\hline Image & Format *.png dan gambar bertipe vector yang dibuat sebagai image dan animasi \\
\hline Audio & Vokal dan instrument dengan format *.wav dan *.mp3 \\
\hline Animasi & Animasi gambar dan tombol yang dibuat sendiri oleh penulis \\
\hline Interaktif & Penggunaan tombol navigasi yang memungkinkan user menuju halaman yang dinginkan \\
\hline
\end{tabular}

\section{B. Perancangan (Design)}

Pada tahapan perancangan (design) akan menentukan secara detil arsitektur, gaya, dan semua material yang akan digunakan pada perangkat lunak multimedia yang akan dikembangkan. Pada penelitian ini, perancangan yang akan dibuat adalah perancangan struktur nafigasi. Gambar 2 menunjukan struktur navigasi media pembelajaran interaktif berbasis multimedia yang akan dikembangkan.

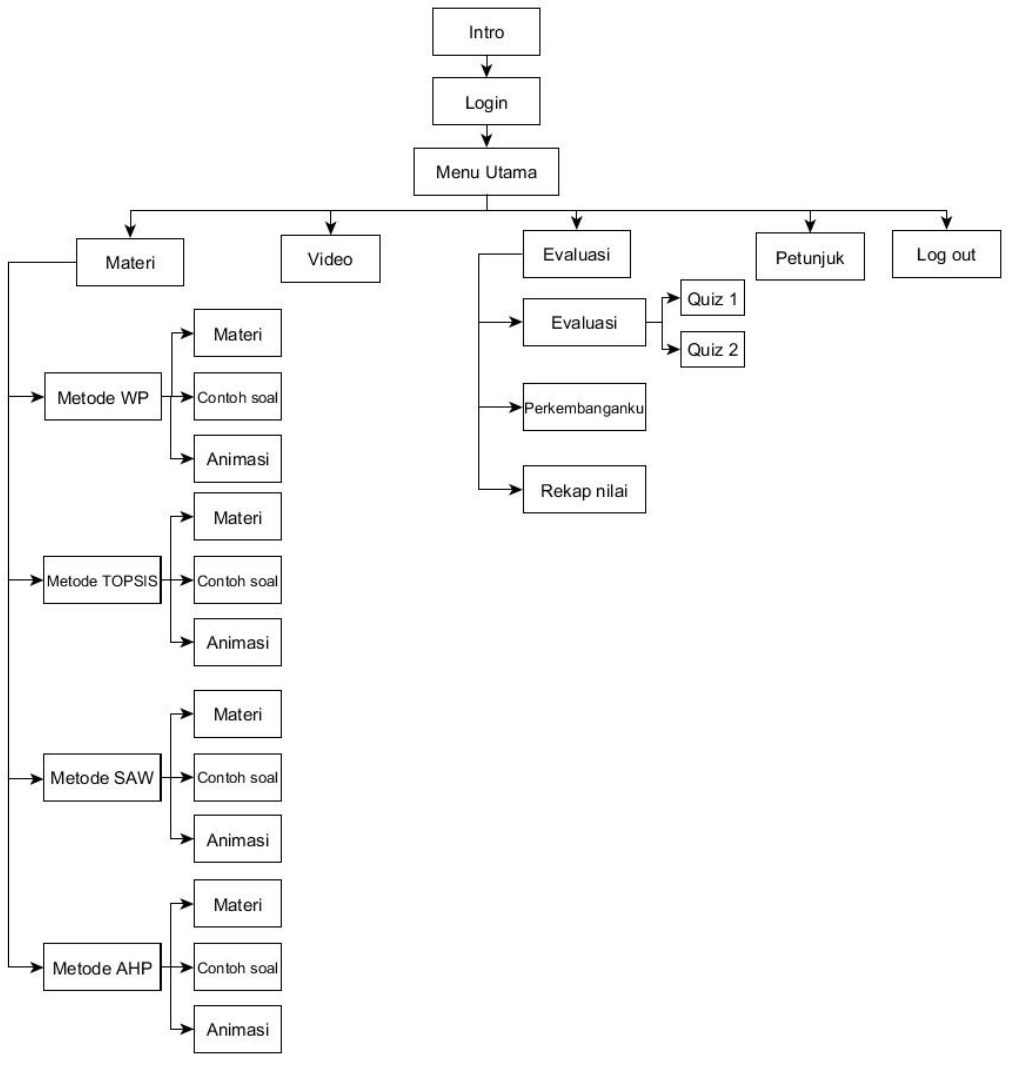

Gambar 2. Struktur Navigasi 


\section{Pengumpulan Bahan (Material Collcting)}

Pada tahap pengumpulan Bahan (material collecting) dilakukan pengumpulan bahan yang sesuai dengan kebutuhan pengembangan multimedia yang dilakukan. Pada tahap ini material yang diperlukan terkait pembangunan media pembelajaran berbasis multimedia seperti gambar, animasi, audio, pembuatan gambar grafik, foto, dan lain-lain. Bahan-bahan diperoleh dari berbagai sumber internet, koleksi ilmiah, dan hasil buatan penulis. Bahan yang diperlukan untuk membangun media pembelajaran ini berupa file teks, gambar, suara, dan animasi.

\section{Pembuatan (Assembly)}

Pembuatan (assembly) pada tahap ini dilakukan pembuatan semua objek atau bahan multimedia. Proses yang lakukan dalam pengembangan media pembelajaran interaktif berbasis multimedia pada matakuliah sistem pendukung keputusan tahap pertama yang dilakukan adalah membuat gambar latar atau background aplikasi dan Photoshop. Setalah itu proses selanjutnya adalah pembuatan tombol-tombol navigasi aplikasi dimana gambar vektor dipisahkan dengan latar asli kemudian dipindahkan pada desain tombol yang telah dibuat sebelumnya. Setelah gambar background dan tombol-tombol navigasi yang dibutuhkan selesai, selanjutnya membuat gambar karakter sebagai bahan animasi yang dibuat di aplikasi Adobe Ilustrator. Bahan animasi yang dibuat penulis adalah frame gambar dengan variasi gerak yang berbeda, untuk selanjutnya dibuat animasi pada aplikasi Construct 2. Untuk bahan narasi pada penyampaian materi, menggunakan aplikasi Audacity. File suara yang disimpan menggunakan format khusus untuk aplikasi Construct 2 yaitu ogg file dan W4A.

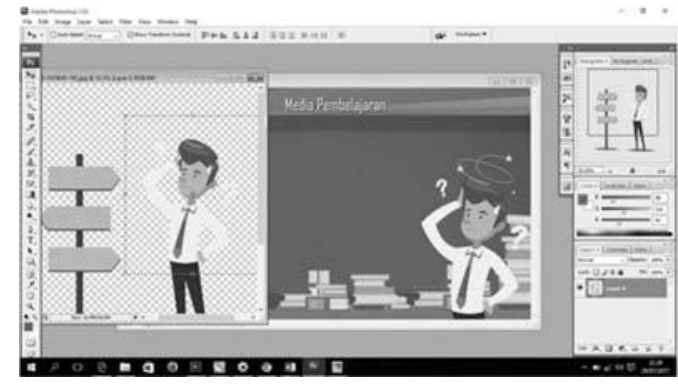

Gambar 3a. Proses Pembuatan Backgorund

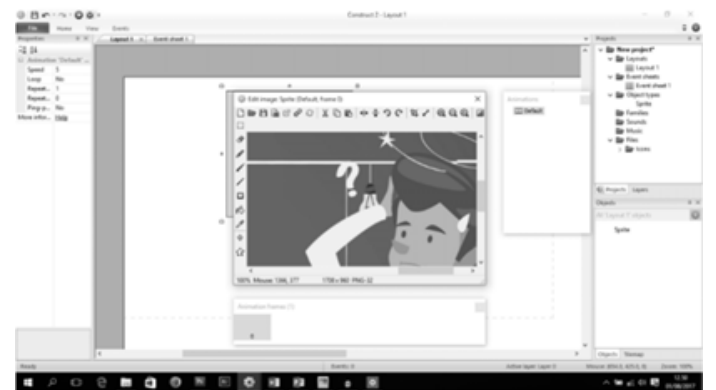

Gambar 3b. Proses Pembuatan Pada Contruct 2

Media pembelajaran berbasis multimedia ini dibuat menggunakan aplikasi Construct 2, termasuk navigasi dan perancangan user interface atau tampilan antar muka pengguna. Pada aplikasi Construct 2 pembuatan animasi berdasarkan jumlah frame gambar yang ditambahkan, semakin banyak frame dan variasi gerak pada gambar, maka animasi akan semakin baik. Pembuatan animasi menggunakan sprite animasi pada construct 2. Selanjutnya pemberian event sheet yang berguna untuk memberi perintah-perintah atau navigasi antar tampilan dan tombol-tombol yang terdapat pada aplikasi media pembelajaran.

\section{E. Pengujian (Testing)}

Pengujian (testing) dilakukan setelah menyelesaikan tahap pembuatan (assembly) akan diuji kepada pengguna dengan memberikan pertanyaan-pertanyaan mengenai aplikasi media pembelajaran yang telah dibangun dan informasi yang terkait dalam aplikasi. Hasil pengujian tersebut diisi oleh mahasiswa dan dosen mata kuliah sistem pendukung keputusan sebagai pengguna aplikasi.

\section{F. Distribusi (Distribution)}

Pada tahap ini akan dilakukan implementasi serta evaluasi terhadap plikasi akan dijalankan. Pendistribusian media pembelajaran dilakukan dengan penyebaran link media pembelajaran. Untuk penyebaran link menggunakan sosial media sebagai media penyebaran link media pembelajaran, seperti Facebook, Whatsapp, Twitter dan Instagram.

\section{HASIL DAN PEMBAHASAN}

Pada media pembelajaran ini membahas tentang materi-materi pada sistem pendukung keputusan, dengan pokok bahasan yang dibahas pada media pembelajaran adalah seperti pembahasan metode Simple Adaptive Weighting (SAW). Weight Product (WP), Technique for Order of Preference by Similarity to Ideal Solution (TOPSIS) dan Analytical Hierarchy Process (AHP). Pada media pembelajaran ini menggunakan pendekatan multisensori sehingga pada media pembelajaran ini dilengkapi dengan penjelasan materi secara text dan narasi yang dilengkapi dengan animasi, gambar penjelas serta evaluasi berupa latihan pengerjaan soal. 


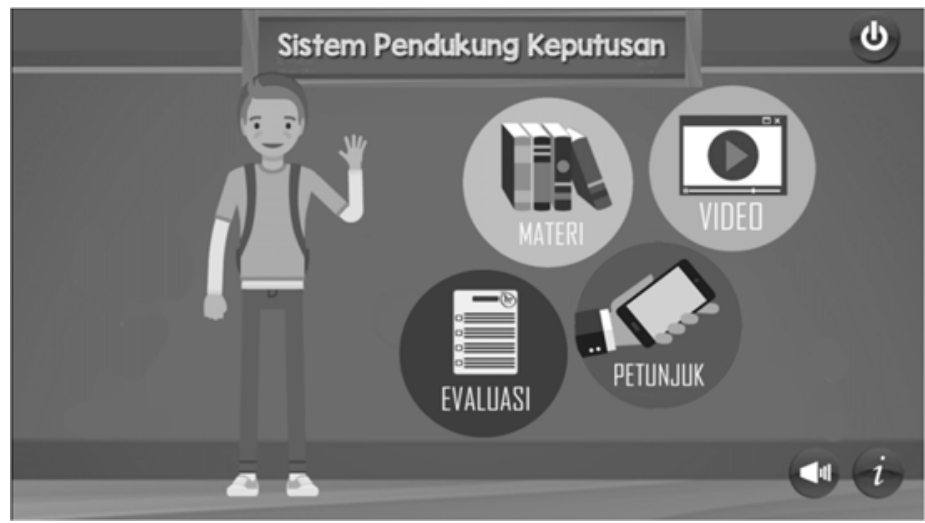

Gambar 4. Media Pembelajaran Sistem Pendukung Keputusan

Pada menu evaluasi terdapat menu quiz yang berisi soal-soal SPK. Soal quiz bertujuan untuk mengetahui sejauh mana pemahaman mahasiswa terhadap materi SPK yang telah dipelajarai pada menu materi yang ada pada media pembelajarn ini.

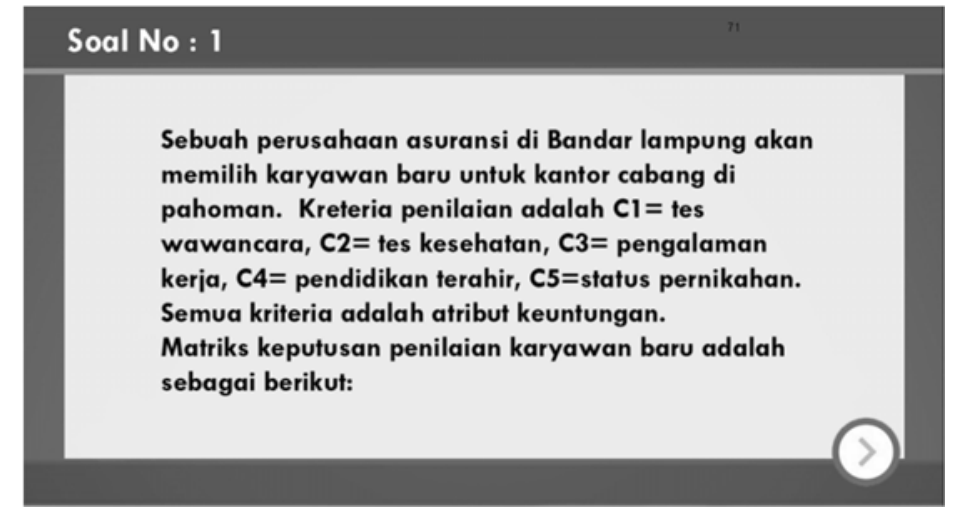

Gambar 5. Soal Quiz Pada Media Pembelajaran Sistem Pendukung Keputusan

Untuk mengetahui apakah mediap pembelaaran yang telah dibuat telah sesui dengan kebutuhan maka diperlukan pengujian yang akan diuji kepada pengguna dengan memberikan kuesioner mengenai media pembelajaran yang telah dibangun. Kuesioner tersebut diisi oleh mahasiswa dan dosen mata kuliah sistem pendukung keputusan sebagai pengguna aplikasi. Butir pertanyaan didasari beberapa kkriteria untuk menilai media pembelajaran multimedia, diantaranya: 1) Kemudahan navigasi, yaitu multimedia interaktif dirancang sesederhana mungkin sehingga pembelajar mampu mempelajarinya dengan mudah; 2) Kandungan kognisi, yaitu kandungan pengetahuannya jelas; 3) Presentasi informasi, yaitu informasi yang disajikan jelas; 4) Integrasi media, yaitu multimedia harus mengintegrasikan aspek pengetahuan dan ketrampilan bahasa yang harus dipelajari; 5) Artistik dan estetika, yaitu multimedia harus mempunyai tampilan yang menarik dan estetika yang baik; 6) Fungsi secara keseluruhan, yaitu multimedia memberikan pembelajaran yang diinginkan oleh pengguna (Munir, 2009). Setelah dilakukan pengujian dan pengisian kuesioner oleh 38 responden didapatkan hasil pengujian seperti pada gambar 6 dibawah ini.

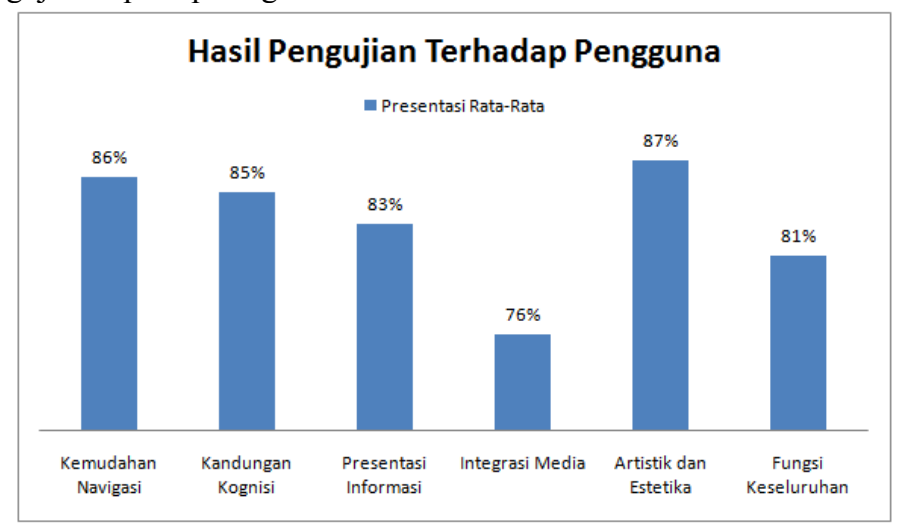

Gambar 6. Hasil Pengujian Terhadap Pengguna 
Berdasarkan hasil dari kuesioner menunjukan nilai rata-rata untuk semua pertanyaan adalah $83 \%$, maka aplikasi media pembelajaran sistem pendukung keputusan berbasis multimedia memiliki nilai kategori baik, sehingga aplikasi dikatakan layak untuk digunakan sebagai media pembelajaran pendukung pada mata kuliah sistem pendukung keputusan.

\section{SIMPULAN DAN SARAN}

\section{A. Kesimpulan}

Berdasarkan penelitian yang telah dilakukan dapat disimpulkan bahwa proses pengembangan media pembelajaran sistem pendukung keputusan berbabsis multimedia meliputi tahap concept, design, material collecting, assembly, testing dan distribution. Penerapan metode multisensori pada media pembelajaran sistem pendukung keputusan berbasis multimedia dilakukan dengan menerapkan unsur-unsur tiga gaya belajar yaitu, Visual, Auditori dan Kinestetik dengan unsur-unsur yang sama pada multimedia seperti, suara, teks, gambar, animasi, video dan evaluasi berupa soal-soal latihan. Ditinjau dari tanggapan dan respon pengguna terhadap media pembelajaran sistem pendukung keputusan mendapatkan nilai rata-rata keseluruhan sebesar $83 \%$ dan termasuk dalam kategori Baik.

\section{B. Saran}

Melihat dari hasil penelitian dan pengembangan yang telah dilakukan peneliti, ada beberapa saran untuk peneliti selanjutnya diantaranya dapat menyajikan materi yang lebih luas sehingga tidak hanya membahas tentang metode-metode dalam SPK saja. Selain itu, perlu diadakan penelitian lebih lanjut dan mendalam mengenai efektifitas penggunaan media pembelajaran yang telah dibuat berkaitan dengan peningkatan motivasi belajar mahasiswa, pemahaman, maupun aspek-aspek lain yang nantinya berguna bagi kemajuan dunia pendidikan.

\section{DAFTAR PUSTAKA}

Arief S. Sadiman, dkk.2009. Media Pendidikan, Pengertian, Pengembangan dan Pemanfaatan. Jakarta: Rajawali Press.

Darma, J. S., Ananda, S. (2009). Buku Pintar Menguasai Internet. Media Kita : Jakarta.

Falahudin, I. (2014). Pemanfaatan Media dalam Pembelajaran. Widyaswara Network Jurnal: Edisi 1 No. 4 , Oktober - Desember 2014, p.104-117.

Hoftsetter, F. T. (2001). Multimedia Literacy, Third edition. McGraw-Hill International Edition : New York.

Munir. (2009). Pembelajaran Jarak Jauh: Berbasis Teknologi Informasi dan Komunikasi. CV. Alvabeta : Bandung.

Praveen. 2011. What is Multisensory Teaching Techques. http://www.lexiconreadingcenter.org/what-ismultisensory-teaching-techques.html. Diakses pada : 16 Juli 2017.

Priyanto, D. (2009). Pengembangan Multimedia Pembelajaran Berbasis Komputer. Jurnal INSANIA: Vol. 14, No. 1, Jan-Apr 2009, p. 92-110.

Roblyer, M.D. \& Doering, A.H. (2010). Integrating Educational Technology into Teaching. Boston: Pearson.

Soetopo, A. H. (2003). Multimedia Interaktif dengan Flash. Graha Ilmu: Jakarta.

Sudjana, N., \& Rivai A. (2011). Media Pengajaran. Bandung: Sinar Baru Algesindo.

Yoanes, B., Hubbany, S., \& Hartanto, A. A. (2010). Teknologi Multimedia. Alex Media Komputindo : Jakarta. 